\title{
AVALIAÇÃO DA EXPOSIÇÃO E DA INTERRUPÇÃO DA NICOTINA DURANTE A CICATRIZAÇÃO EM RATOS WISTAR
}

\section{Ana Rosa Crisci}

Docente Adjunto $\mathrm{V}$ do departamento de morfologia da Centro Universitário Barão de Mauá, Ribeirão Preto (SP), Brasil; E-mail: criscicozac@netsite.com.br

Carla Simões Cassemiro

Cristiane Aparecida Borges

Fernanda Caravalho Oliveira

Centro Universitário Barão de Mauá, Ribeirão Preto (SP), Brasil

\section{Maria Helena Simões Jorge}

Mestre em Ciências Biológicas (Entomologia) pela Universidade de São Paulo (USP), Brasil; Docente da Organização Educacional Barão de Mauá e do Colégio Oswaldo Cruz
RESUMO: As evidências clínicas e experimentais demonstram que o uso da nicotina tem efeitos deletéricos sobre a cicatrização. Entretanto, muitas dúvidas ainda existem entre cirurgiões e equipes de saúde em relação ao tempo de interrupção que antecede esses procedimentos. Nesta pesquisa, os ratos Wistar foram divididos em 3 grupos (G1, G2 e G3) que receberam doses diárias de $2 \mathrm{mg} / \mathrm{kg}$ de nicotina subcutânea durante 4 semanas. O G1 não interrompeu o uso por dez dias após a cirurgia de retirada de retalho cutâneo; o G2 interrompeu o uso da nicotina uma semana antes da cirurgia; e o G3 interrompeu por duas semanas antes da cirurgia, não fazendo mais uso durante os dez dias após esse procedimento. A análise dos parâmetros de cicatrização na fase proliferativa foi feita através de microscopia de luz e corados pelo H.E. e colorações especiais para análise de colágeno (Tricrômico de Masson e Verhoeff). Encontrou-se no G1 a presença de crosta fibrinoleucocitária, uma visível desorganização do colágeno e um deficiente tecido de granulação quando comparados aos G2 e G3. Dos escores médios dos três grupos obteve-se $p=0,028$ considerados significativos e no pós-teste Tukey-Kramer foram encontradas diferenças estatísticas significativas entre os G1 e G3 $(\mathrm{p}<0,05)$. Na análise do tecido de granulação $(\mathrm{p}=0,0008)$ e do colágeno $(\mathrm{p}=0,049)$ também se obteve diferença estatística significativa. Pode-se concluir que na interrupção por uma ou duas semanas obteve-se uma melhor e mais eficiente cicatrização, podendo, portanto, extrapolar esses resultados para orientação do pré e pós-cirúrgicos de pacientes tabagistas.

PALAVRAS-CHAVE: Cicatrização; Colágeno; Nicotina.

\section{ASSESSMENT OF EXPOSURE AND INTERRUPTION OF NICOTINE DURING WOUND HEALING IN WISTAR RATS}

ABSTRACT: Clinical and experimental evidences show that the use of nicotine has deleterious effects on wound healing, although there are still many doubts among surgeons and health teams with regard to the interruption that should precede interventions. Wistar rats, divided into three groups (G1, G2 and G3), received daily subcutaneous doses of $2 \mathrm{mg} / \mathrm{kg}$ nicotine during 4 weeks. G1 did not interrupt use during 10 days after surgery; $\mathrm{G} 2$ interrupted nicotine use a week prior to surgery; G3 interrupted during two weeks before surgery and did not take nicotine during ten days after surgical procedure. Woundhealing parameters during the proliferation phase were analyzed by light microscopy and stained with HE and special stains for collagen analysis (Masson's Trichromium and Verhoeff). A fibrin-leukocyte crust, a visible disorder of collagen and a granulation tissue deficiency occurred in G1 when compared to G2 and G3. Average scores of the three groups $(p=0.028)$ were significant and significant statistical differences between $\mathrm{G} 1$ and $\mathrm{G} 3$ existed $(\mathrm{p}<0.05)$ by Tukey-Kramer's post-test. Statistically significant difference existed in the granulation 
$(p=0.0008)$ and collagen $(p=0,049)$ tissues. Results show that a greater and more efficient wound-healing occurred when nicotine was interrupted for one or two weeks, which may be recommended for smoking patients in the pre- and post-surgery periods.

KEY WORDS: Wound Healing; Collagen; Nicotine.

\section{INTRODUÇÃO}

Qualquer tipo de cirurgia em que a indicação seja a realização de um retalho cutâneo vários fatores contribuem para o insucesso da mesma, dentre eles podese atribuir causas extrínsecas e intrínsecas. Como causas extrínsecas pode-se incluir as infecções, hipotensão e desnutrição, a essas poderíamos ainda somar falhas técnicas e de planejamento; porém todas essas causas podem ser controladas com uma orientação adequada durante o pré e pós-operatório. Como principal fator intrínseco pode-se citar o fluxo sanguíneo inadequado na região do retalho (KERRIGAN, 1983).

Segundo Campos et al. (2010), a nicotina é o principal componente vasoativo da fumaça do tabaco, inodora e incolor, e quando inalada ou injetada pode liberar catecolaminas e resultar em vasoconstrição e diminuição da perfusão tecidual.

A nicotina tem sido amplamente identificada como o composto mais importante causador de efeitos negativos, tanto no sistema cardiovascular como na microcirculação da pele. A nicotina diminui o fluxo sanguíneo cutâneo em $30 \%$ a $40 \%$ devido estímulo de liberação de catecolaminas e norepinefrina, produzindo vasoconstrição. Na microcirculação atua induzindo ativação e agregação plaquetária, produzindo microtrombo. Além disso, altera o processo de cicatrização de feridas ao diminuir a proliferação de fibroblasto e macrófago, além de estimular as catecolaminas, que são cofatores em formação de calonas, as quais inibem 0 processo de epitelização (LEAL et al., 2004).

Há décadas várias pesquisas têm demonstrado que o tabagismo tem um impacto negativo na reparação de feridas e tecidos. Isto tem sido demonstrado em destaque significativo na cicatrização após cirurgia, feridas suturadas, deiscência em todas as especialidades cirúrgicas de tecidos e infecções no local da sutura (SORENSEN, 2012).
Da mesma forma, vários estudos já comprovaram as ações maléficas da nicotina na vascularização de retalhos, especialmente em retalhos cutâneos, ainda hoje não se compreende muito sobre os efeitos da interrupção do tabagismo previamente a uma cirurgia (SALLES et al., 2008).

Mosely e Finseth (1977) descreveram um caso onde relataram os efeitos benéficos de parar de fumar após uma úlcera na ponta dos dedos.

Vários estudos na literatura investigaram os efeitos da nicotina sobre o processo de cicatrização. A fumaça do cigarro contém mais de quatro mil substâncias químicas, muitas das quais podem contribuir para os efeitos reforçadores do tabaco. Contudo, a maioria dos estudos pré-clínicos e clínicos demonstra que a nicotina é o principal agente responsável pelo desenvolvimento da dependência ao tabaco (PLANETA; CRUZ, 2005).

A cicatrização de feridas consiste em perfeita e coordenada cascata de eventos celulares e moleculares que interagem para que ocorra a reconstituição dos tecidos lesados. É processo dinâmico que envolve fenômenos bioquímicos e fisiológicos. Vários estudos experimentais, realizados em diferentes condições, descreveram efeito inibitório da nicotina sobre a migração e diferenciação dos queratinócitos, levando ao atraso da reepitelização (SIMÕES et al., 2009).

Fang e Svoboda (2005), estudando fibroblastos humanos, cultivados com diferentes concentrações de nicotina, observaram que existia inibição da diferenciação dos fibroblastos a miofibroblastos e atribuíram a isto à diminuição da contração das feridas.

O tabagismo é considerado pela Organização Mundial da Saúde (OMS) a principal causa de morte evitável em todo o mundo. A OMS estima que um bilhão e 200 milhões de pessoas, no mundo, sejam fumantes. $\mathrm{O}$ total de mortes decorrentes do hábito de fumar atingiu a cifra de 4,9 milhões de mortes anuais, o que corresponde a sete mortes por minuto (SIMÕES et al., 2009).

O cigarro provoca prejuízo anual para o sistema público de saúde de pelo menos $\mathrm{R} \$ 338$ milhões, o equivalente a $7,7 \%$ do custo de todas as internações e quimioterapias no nosso País. Para o cálculo foram consideradas as custas de 32 doenças comprovadamente associadas ao tabagismo, no ano de 2005. Estima-se que $22,4 \%$ da população brasileira fumem (SIMÕES et al., 2009). 
Estes custos elevados aumentam a importância da busca de estratégias de abordagem terapêutica que facilitem o processo de tratamento de reparo de tecidos. Diante do exposto, viu-se a necessidade de contribuir sobre os efeitos da interrupção do tabagismo previamente a uma cirurgia.

Visando, sobretudo, orientar a prática clínica no aconselhamento aos pacientes tabagistas quando diante de situações nas quais seja necessário atuar frente ao uso do cigarro durante intervenção cirúrgica, objetivando uma melhor qualidade de cicatrização cutânea.

Deste modo, o quanto a interrupção da droga seja por uma ou duas semanas seria fator preponderante para haver uma melhora no fluxo sanguíneo e consequentemente uma cicatrização mais eficiente.

O profissional de enfermagem membro de uma equipe de saúde tem o propósito de orientar os pacientes no pré-operatório quanto à interrupção do cigarro, pois isso lhes trará maiores benefícios no pós-operatório, acelerando a sua recuperação.

\section{MATERIAL E MÉTODOS}

Segundo o modelo de Antônio Carlos Gil (2006), este estudo caracteriza uma investigação experimental, no qual o objeto de estudo, a morfologia da pele, é caracterizada por variáveis, relacionadas à variabilidade da nicotina injetável anteriormente às lesões cutâneas.

A observação dos efeitos que as variáveis produzem no objeto constitui a pesquisa, em sua relação causa-efeito. Sendo considerado o delineamento mais prestigiado na ciência, na pesquisa experimental o pesquisador é um agente ativo (GIL, 2006).

$\mathrm{O}$ experimento segue as regulamentações propostas na Lei ${ }^{\circ} 11.794$, de 08 de outubro de 2008, que estabelece procedimentos para o uso científico de animais e foi submetido à aprovação do Comitê de Ética em Pesquisa e Experimentação Animal (CEPAN) do Centro Universitário Barão de Mauá (protocolo $\mathrm{n}^{\circ}$ 192/2013).

\subsection{CARACTERIZAÇÃO DA AMOSTRA}

No presente estudo serão utilizados 30 ratos da linhagem Wistar procedentes do Biotério do Centro
Universitário Barão de Mauá, cujos pesos variaram entre 250 a 300 g. Esses animais foram distribuídos em 3 grupos com 10 animais cada um e mantidos no biotério em condições controladas de temperatura e em regime de luz de $12 \mathrm{hs} / 12 \mathrm{hs}$. Os animais dos 3 grupos receberam $2 \mathrm{mg} / \mathrm{kg}$ de nicotina (Sulfato L-1 Metil-2(3-Piridil)Pirrolidina Sulfato; grau II; PM 422-6) por via subcutânea; a nicotina foi adquirida pela SIGMA, diluída em solução salina para a concentração de $1 \mathrm{mg} / \mathrm{ml}$.

O grupo 1, formado por 10 ratos, receberá tratamento diário com nicotina durante 4 semanas, procedimento cirúrgico e continuidade do tratamento por mais 10 dias do pós-operatório.

O grupo 2, formado por 10 ratos, receberá tratamento com nicotina por quatro semanas, interrupção do tratamento por uma semana, procedimento cirúrgico e manutenção sem tratamento por 10 dias do pósoperatório.

O grupo 3, formado por 10 ratos, receberá tratamento diário com nicotina por quatro semanas e interrupção por duas semanas, procedimento cirúrgico e manutenção sem tratamento por mais 10 dias do pósoperatório, como segue o esquema abaixo.

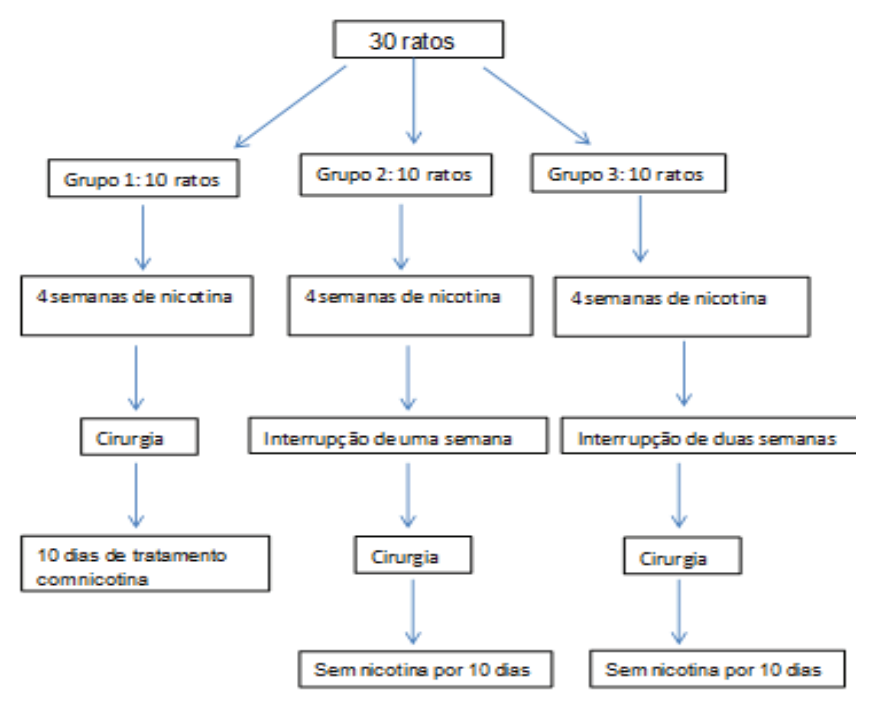

Figura 1. Esquema da divisão dos grupos com seus tratamentos e períodos

Fonte: autoria do próprio autor.

\subsection{PROCEDIMENTOS CIRÚRGICOS}

Para o procedimento cirúrgico os animais foram anestesiados por via intramuscular com cloridrato de ketamina $100 \mathrm{mg} / \mathrm{kg}$ e cloridrato de xilazina $6 \mathrm{mg} / \mathrm{kg}$. 
Após a anestesia e a padronização da lesão (SILVA, 2006), foi realizado um corte através de incisão, com auxílio de bisturi (cabo no 3 e lâmina $n^{0} 15$ ) na área quadrangular demarcada de aproximadamente $1,0 \times 1,0 \mathrm{~cm}$ (Figura 1D) que atingiu o tecido subcutâneo, com tesoura de íris reta de $11 \mathrm{~cm}$ e pinça de Adson, retirou-se o fragmento expondo-se a fáscia dorsal muscular (Figura 1F). A hemostasia foi realizada, quando necessária, através de tamponamento compressivo com gaze por dois minutos.

O sacrifício dos animais em câmera de dióxido de carbono, conforme aprovação do comitê de ética animal, ocorreu 10 dias após a cirurgia.
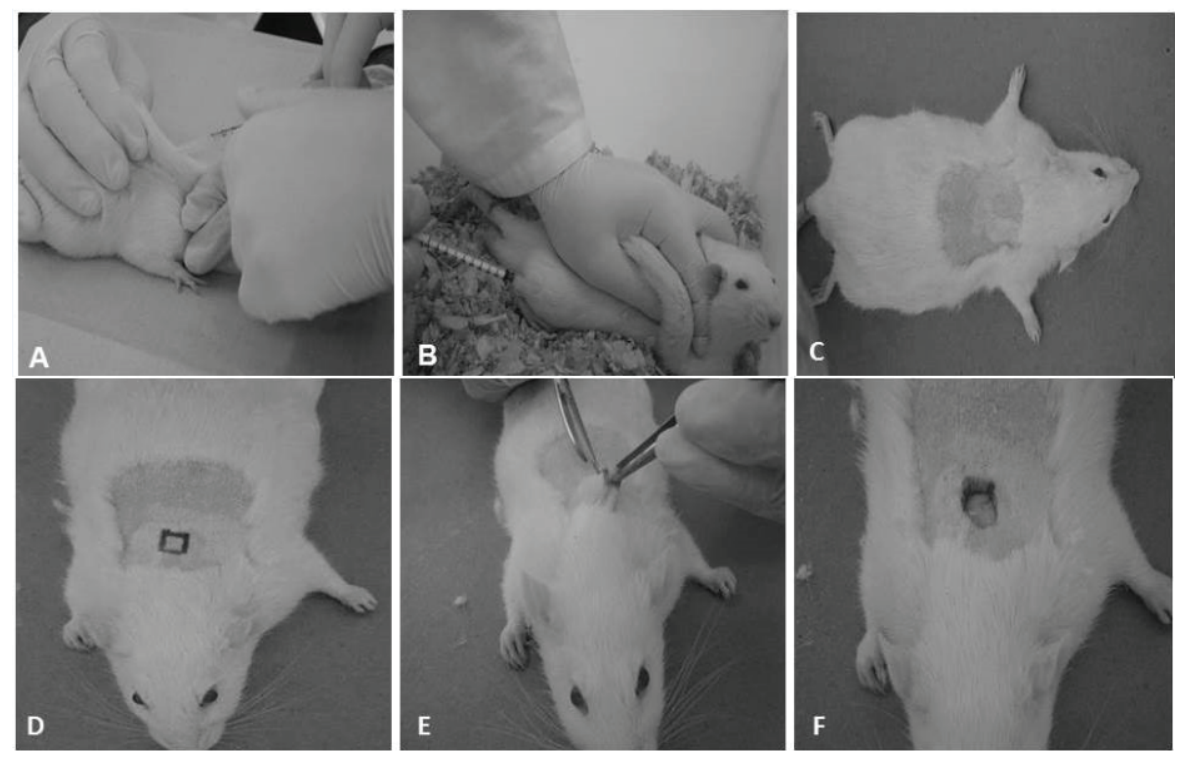

Figura 2. Fotografias dos Procedimentos Cirúrgicos

2A: injeção de nicotina por via subcutânea; $2 \mathrm{~B}$ : anestesia intramuscular pré-cirurgia; $2 \mathrm{C}$ : tricotomia; 2D: delimitação da área a ser seccionada; 2E: secção; 2F: área seccionada para estudo da cicatrização

\subsection{ANÁLISES HISTOLÓGICAS}

Para a análise histológica foram coletadas amostras de pele, removidas com tesouras e colocadas imediatamente em formol $10 \%$ por um período de 24 horas para os procedimentos histológicos de nicotina, corados pela hematoxilina e eosina (H.E.), Tricrômico de Masson e pelo Verhoeff.

$\mathrm{Na}$ análise dos cortes corados com Tricrômico de Masson, uma técnica tradicional, as fibras colágenas apresentam-se de cor azul e com a coloração de Verhoeff uma coloração especial para evidenciar fibras colágenas em vermelho, fibras elásticas em preto e outras estruturas como hemácias, músculos e citoplasma em amarelo (MENESES et al., 2011).

As lâminas foram observadas em microscopia de luz, e na análise com H.E., os dados histopatológicos foram transformados em escores e quantificados de acordo com a técnica de MYERS modificada (Tabela 1) (MEDEIROS et al., 1999).
Tabela1. Utilizada para calcular os escores das feridas da cicatrização

\begin{tabular}{lcccccc}
\hline Variáveis & $\mathbf{0}$ & $\mathbf{+ 1}$ & $\mathbf{+ 2}$ & +3 & +4 & Fator \\
\hline Crosta & & & & & & -1 \\
Regeneração & & & & & & +5 \\
epitelial & & & & & & \\
Tec.de & & & & & & +5 \\
granulação & & & & & & +5 \\
Fibroblasto & & & & & & +10 \\
Colágeno & & & & & & \\
\hline
\end{tabular}

As intensidades das variáveis ( 0 a 4 ) foram multiplicadas por fatores positivos ou negativos baseados na sua importância para a cicatrização. A soma desses produtos corresponde ao escore total para cada animal.

\subsection{ANÁLISE ESTATÍSTICA}

Para cada animal foram calculados os escores, a média e o erro padrão de cada grupo, e os escores de cada variável. 
Para análise estatística os resultados foram avaliados por análise de variância (ANOVA), onde foram adotados: $>0,05$ não significativo; $<0,05^{*}<0,01 * *<$ $0,001 * * *$ para determinar as diferenças existentes entre os grupos. Foi usado o teste de Tukey-Kramer como pós-teste para comparar cada par de médias. Foram consideradas significativas comparações com $\mathrm{P}$ igual ou menor a $0,05\left(\mathrm{p}<0,05^{*}\right)$.

\section{RESULTADOS}

\subsection{ANÁLISE HISTOPATOLÓGICA}

Durante as aplicações de nicotina observouse uma agitação muito grande nos animais, seguida de taquicardia; houve perda de um animal do grupo 1, ficando, portanto, o grupo 1 com 9 animais.

$\mathrm{Na}$ análise histopatológica do grupo 1observouse que houve a formação de uma acentuada crosta fibrinoleucocitária, a formação de tecido de granulação com neovasos e fibroblastos, houve também um discreto início de reepitelização abaixo da crosta fibrinoleucocitária (Figura 2A e 2D).
No mesmo grupo com as colorações especiais, Tricrômico de Masson e Verhoeff observou-se a presença de fibras colágenas com disposição muito irregular e poucos fibroblastos (Figura 3A e D).

No grupo 2 encontrou-se uma maior reepitelização sem a presença de crosta fibrinoleucocitária (Figura 2B), tecido de granulação com presença de neovasos e fibroblastos (Figura 2E), com formação de fibras colágenas mais organizadas (Figura 3E).

$\mathrm{Na}$ análise histopatológica do grupo 3 observouse uma reepitelização mais acentuada, porém em alguns animais isso não ocorreu, ao contrário, encontrouse presença de crosta fibrinoleucocitária com colônia de bactérias semelhante às encontradas no grupo 1 , provocadas pelo atrito com a grade da gaiola, há presença de vasos com hemácias (Figura 3F) e acentuado tecido de granulação com fibroblastos, porém, a formação de fibras colágenas ainda está muito inicial apresentando-se muito desorganizada (Figura 3F).

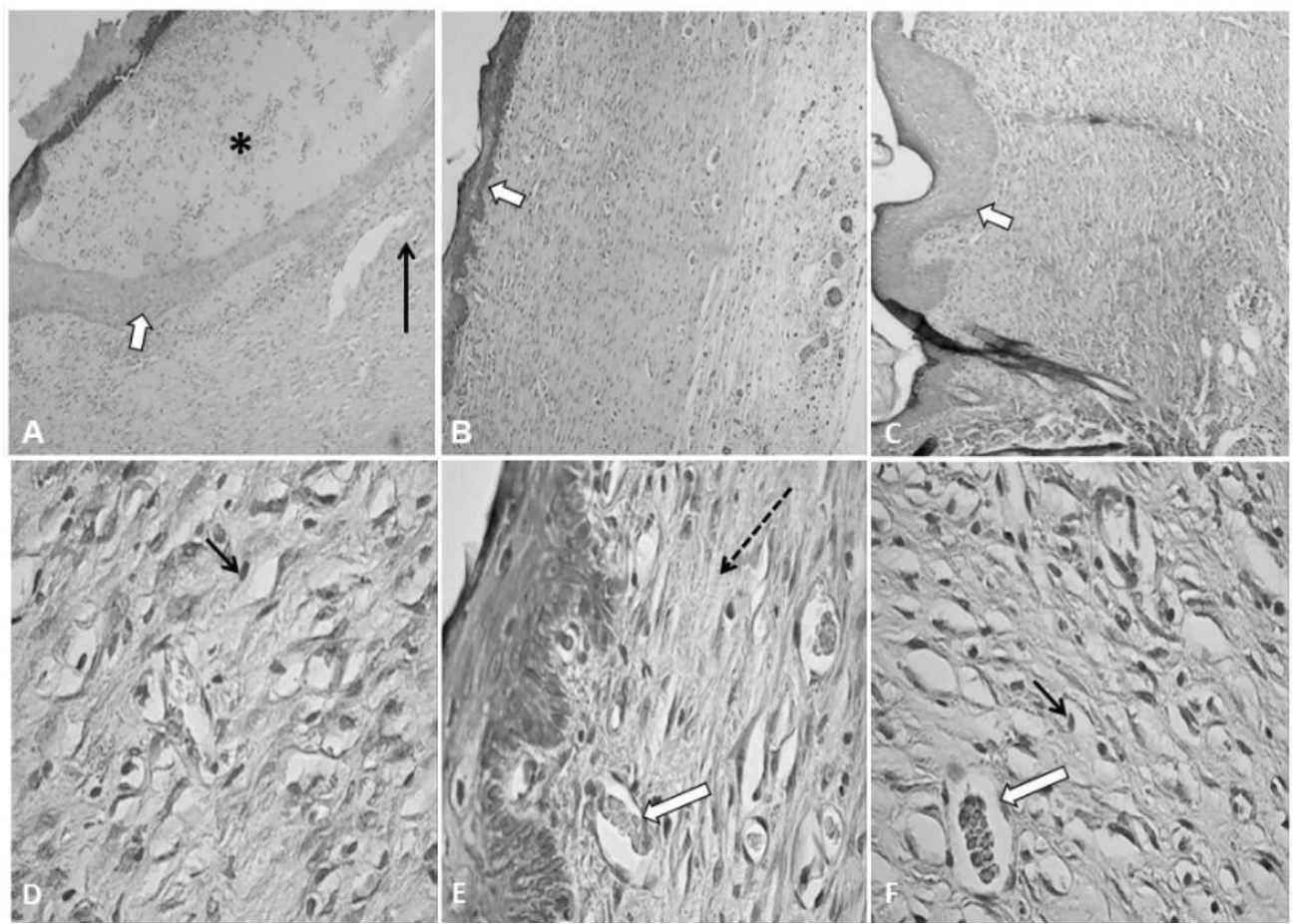

Figura 3. Fotomicrografias dos aspectos histopatológicos das áreas de cicatrização após 10 dias da cirurgia (H.E.) (4x e 20x). Em A e D, grupo G1; Em B e E, grupo G2; Em C e F, grupo G3. Seta larga curta: reepitelização; *crosta fibrinoleucocitária; seta longa: tecido de granulação; seta pontilhada: fibras colágenas; seta curta: fibroblastos; seta larga longa: neovasos. 


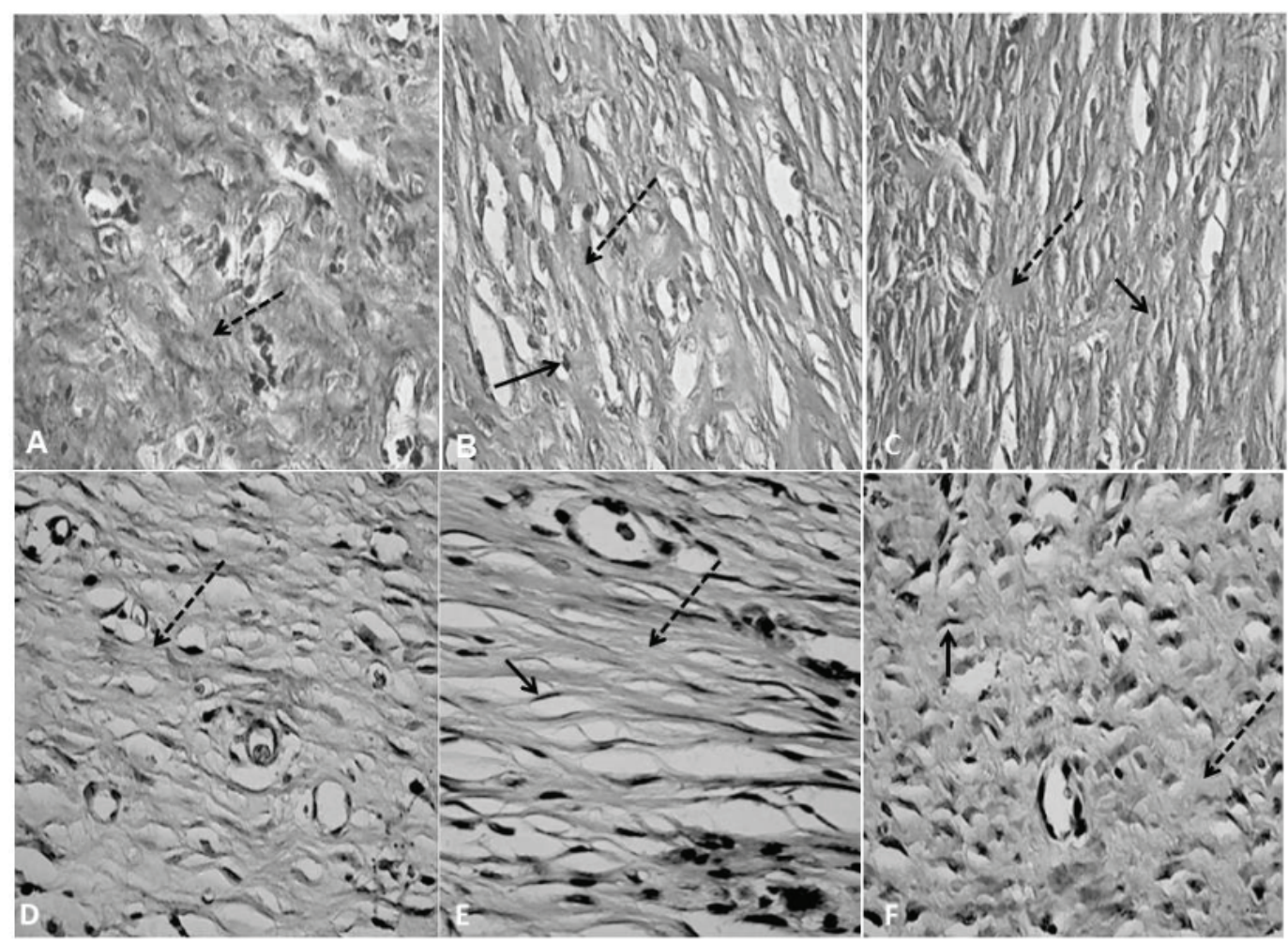

Figura 4. Fotomicrografias dos aspectos histopatológicos das áreas de cicatrização após 10 dias da cirurgia. (Tricromico de Masson A, B, C e Verhoeff D, E, F) (20x). Em A e D, grupo G1; Em B e E, grupo G2; Em C e F, grupo G3. Setas pontilhadas: fibras colágenas; seta curta: fibroblastos.

\subsection{RESULTADOS ESTATÍSTICOS}

Foi aplicado o teste estatístico ANOVA para comparar os escores médios dos 3 grupos, obtendo-se $\mathrm{p}=0,0289$, considerados significativos.

O experimento demonstra que o grupo 1 apresenta menor escore total (média $=47,33$ e erro padrão $=6,05$ ), seguido do grupo 2 (média $=57,1$ e erro padrão $=5,39$ ) e o grupo 3 (média $=68,1$ e erro padrão $=3,78$ ) que apresentaram maiores escores (Figura 4).

Como o teste apresentou evidências de que os escores médios não foram todos iguais, comparou-se 2 a 2 e verificando onde estava a diferença. Fez-se o pós-teste Tukey-Kramer, que resultou no seguinte:

Tabela 2. Apresenta os escores médios que não foram iguais

\begin{tabular}{ccc}
\hline Grupos & Diferença entre as médias & Valor de $\mathbf{p}$ \\
\hline G1 e G2 & 9.767 & ns $P>0.05$ \\
G1 e G3 & 20.767 & $* \mathrm{P}<0.05$ \\
G2 e G3 & 11.000 & ns P $>0.05$ \\
\hline
\end{tabular}

Entre os grupos 1 e $2(\mathrm{p}>0,05)$ e os grupos 2 e $3(p>0,05)$ não houve diferença estatística significativa; entre os grupos 1 e $3(p<0,05)$ houve diferença significativa (Figura 5).

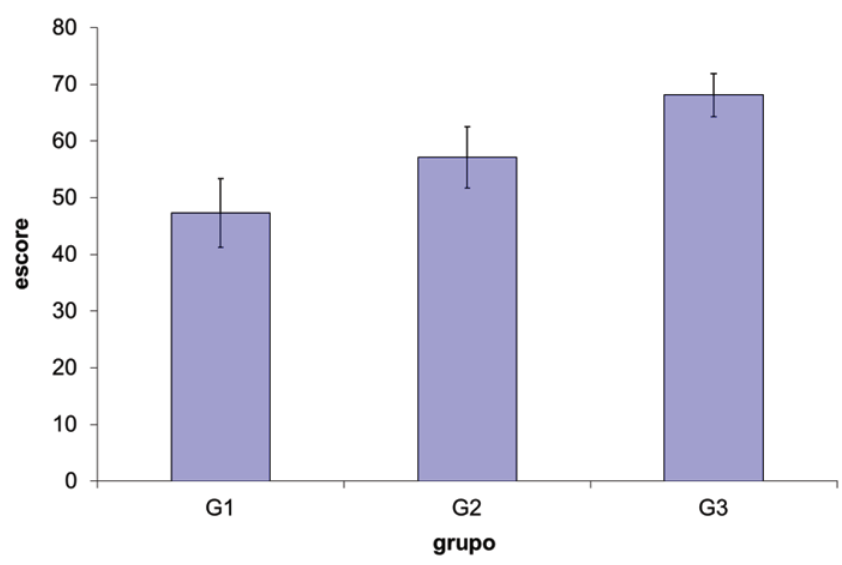

Figura 5. Comparação dos escores médios dos 3 grupos.

A análise da formação dos escores referentes ao colágeno entre os grupos resultou em diferença estatística ( $p=0,049)$. Fez-se o pós-teste Tukey-Kramer, que resultou no seguinte: 
Tabela 3. Apresenta os escores referentes ao colágeno

\begin{tabular}{lcc}
\hline Grupos & Diferença entre as médias & Valor de $\mathbf{p}$ \\
\hline G1 vs. G2 & 0.6000 & ns $P>0.05$ \\
G1 vs. G3 & 1.000 & $* \quad P<0.05$ \\
G2 vs. G3 & 0.4000 & ns $P>0.05$
\end{tabular}

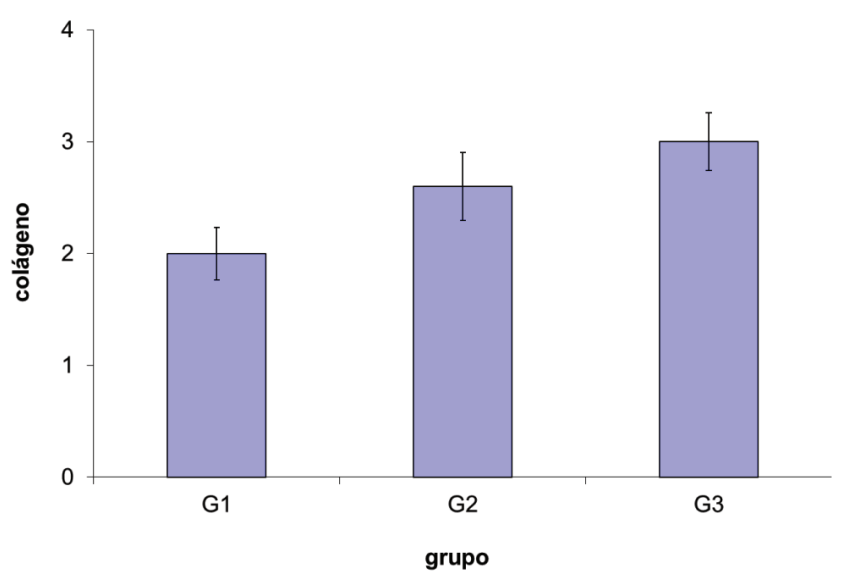

Figura 6. Comparação da quantidade de colágeno nos 3 grupos.

A análise da formação dos escores referentes do fibroblasto entre os grupos não resultou em diferença estatística $(p=0,29)$.

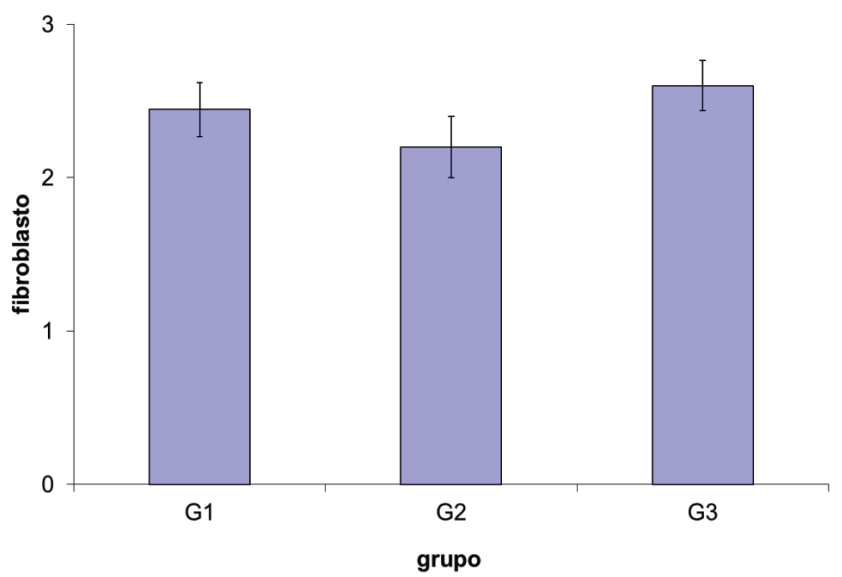

Figura 7. Comparação da quantidade de fibroblastos nos 3 grupos.

A análise da formação dos escores referentes do tecido de granulação entre os grupos resultou em diferença estatística $(p=0,0008)$.

Como o teste apresentou evidências de que os escores médios não foram todos iguais, comparou-se 2 a 2 e verificando onde estava a diferença. Fez-se o teste Tukey-Kramer, que resultou no seguinte:
Tabela 4. Apresenta os escores médios.

\begin{tabular}{ccc}
\hline Grupos & Diferenças entre as médias & Valor de $\mathbf{p}$ \\
\hline G1 e G2 & 0.4889 & ns $\mathrm{P}>0.05$ \\
G1 e G3 & 1.189 & $* * * \mathrm{P}<0.001$ \\
$\mathrm{G} 2$ e G3 & 0.7000 & $* \mathrm{P}<0.05$ \\
\hline
\end{tabular}

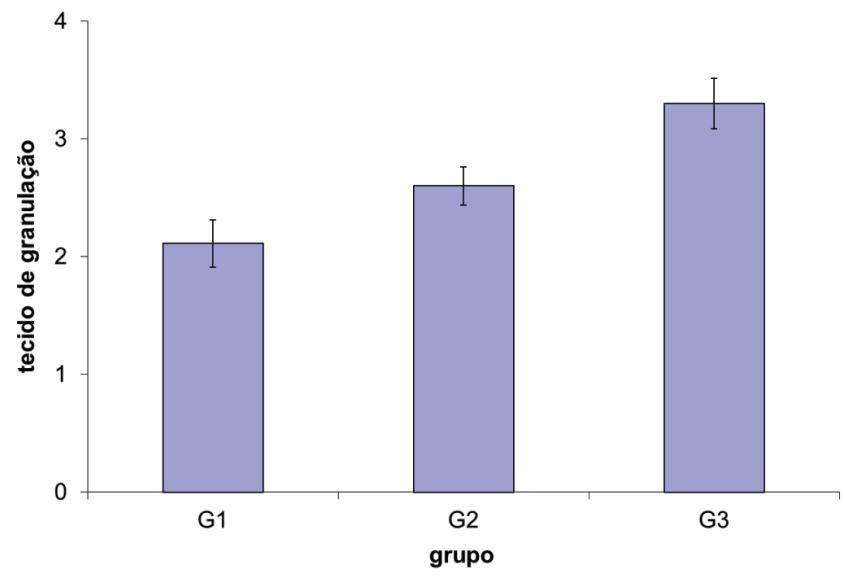

Figura 8. Comparação da quantidade de tecido de granulação nos 3 grupos.

A análise da formação dos escores referentes à regeneração epitelial entre os grupos não resultou em diferença estatística $(p=0,44)$.

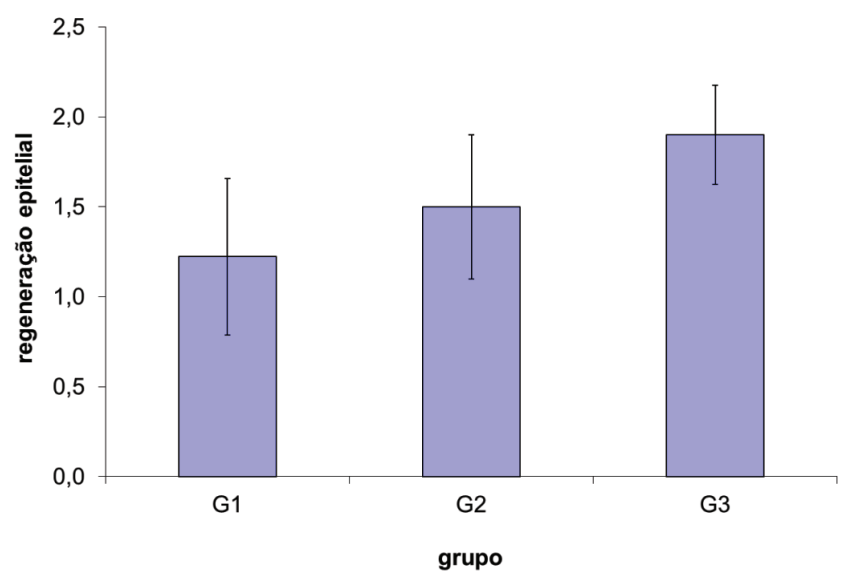

Figura 9. Comparação da regeneração epitelial nos 3 grupos.

\section{DISCUSSÃO}

As deficiências cicatriciais em fumantes são relatadas por diversos autores. Silva (2012), em sua revisão, conclui que a ação vasoconstrictora da nicotina, assim como o aumento da adesividade plaquetária, e também a ligação irreversível do monóxido de carbono à hemoglobina, corroboram para o já conhecido efeito 
de hipóxia tecidual causado pelo cigarro. Esta hipóxia parece prejudicar o processo cicatricial, o que parece ser compreensível do ponto de vista da fisiologia da cicatrização cutânea.

Neste estudo procurou-se minimizar as dúvidas referentes ao uso do cigarro antes e depois de uma intervenção cirúrgica, em consultórios médicos e nos procedimentos pré e pós-operatórios realizados por equipes multiprofissionais.

Segundo Schenfelderetetal (2008), estudos que abordem o tempo de interrupção da nicotina relacionando com a vascularização e cicatrização são extremamente importantes na prática diária da cirurgia plástica.

O rato da linhagem Wistar foi escolhido por ser de pequeno porte, de fácil aquisição e padronização no que diz respeito à idade, peso, sexo, alojamento, alimentação, cuidados de limpeza e manipulação experimental. Ele ainda apresenta muito boa resistência à manipulação e agressão cirúrgica, às infecções e podem ser utilizados em amostras significativas.

De acordo com Santos et al. (2006), a pele de rato apresenta diferença importante em relação à humana que é a ausência de um limite definido entre derme papilar e derme reticular; a derme do rato é mais espessa e não possui tecido subcutâneo (tecido gorduroso), e em ambos os vasos sanguíneos são subdérmicos.

A ferida foi realizada na região dorsal-cervical para dificultar o contato do animal, mesmo assim observou-se no grupo 3, que permaneceu mais tempo na gaiola, que esses animais aumentaram de tamanho em relação aos outros grupos, assim o contato com a grade da gaiola foi inevitável, o que provocou o atrito da região da ferida, provocando em alguns animais uma segunda lesão.

As doses de nicotina de $2 \mathrm{mg} / \mathrm{kg}$ de peso do animal por 4 semanas de exposição simularam um quadro de tabagismo acentuado (GUIMARÃES et al., 2013).

Os resultados foram obtidos a partir da média de escores pré-determinados; foram analisados a presença de crosta, tecido de granulação, regeneração epitelial, presença de fibroblasto e colágeno.

Essas análises são consideradas parâmetros importantes na fase proliferativa da cicatrização que se inicia ao redor do $4^{\circ}$ dia após a lesão e se estende por mais duas semanas aproximadamente.
Para a análise do colágeno optou-se por uma coloração mais específica, o Tricrômico de Masson, porque acredita-se que esta apresenta-se como uma ferramenta fidedigna na avaliação da cicatrização tecidual; sua aplicabilidade fica mais do que clara, já que o novo tecido é formado basicamente por uma matriz de colágeno.

$\mathrm{Na}$ regeneração epitelial os escores médios dos 3 grupos não apresentaram diferença estatística significativa, entretanto, o grupo 1 (grupo que recebeu nicotina sem interrupções), apresentou menor escore médio e pela análise histopatológica foi considerado o mais atrasado em relação à cicatrização, apresentou crosta fibrinoleucocitária.

Segundo Martin (1997), a crosta é formada logo nas fases iniciais da cicatrização sendo composta primariamente por uma concentração de fibrina, agregação plaquetária, embebidas em células sanguíneas.

A regeneração epitelial também não apresentou diferença estatística significativa nos 3 grupos, porém nota-se nos grupos 2 e 3 uma reepitelização mais adiantada em relação ao grupo 1 , esse fato vai de encontro com os resultados obtidos por Zia et al. (2000), que estudaram a capacidade de movimentação dos queratinócitos na reepitelização, os receptores de migração dos queratinócitos são inibidos pela nicotina.

A nicotina exerce também efeitos inibidores sobre o cálcio, que atua como um segundo mensageiro na via de sinalização. Estes resultados ajudam a explicar os efeitos deletérios da nicotina sobre o ferimento de reepitelização e sugerem que o fumo pode atrasar a cicatrização de feridas através da via do receptor nicotínico-mediada.

O tecido de granulação foi analisado; este tecido caracteriza-se por um leito denso de macrófagos, fibroblastos e neovasos suportados por uma matriz de fibronectina, colágeno tipo I e tipo II, além do ácido hialurônico.

Nesta investigação o tecido de granulação apresentou diferença estatística significativa entre os 3 grupos estudados e na comparação entre os grupos 1 e 3 a diferença foi ainda maior ( $p<0,001)$, entre os grupos 2 e 3 a diferença também foi significativa $(p<0,05)$.

De acordo com Silva (2012), o tecido de granulação é importantíssimo para reparação tecidual, 
mas a sua presença em intensidades variadas, em períodos intermediários ou tardios é comum, não sendo um parâmetro auxiliar para avaliação do grau de cicatrização, pois podem ser encontradas feridas em graus avançados de colagenização ou reepitelização, com diferentes intensidades de tecido de granulação.

A quantidade de fibroblastos nos 3 grupos não foi estatisticamente significativa, embora os fibroblastos sejam importantes componentes do tecido de granulação, a reparação e remodelação do tecido são alterados por tabaco, principalmente através deste sobre a estrutura e função dos fibroblastos.

Em concordância com Wong (2004), em camundongos cuja pele foi submetida à ação da nicotina apresenta-se uma redução de proteínas da matriz extracelular assim como uma alteração da renovação destas proteínas extracelulares.

Vários estudos mostraram que o fumo do cigarro pode prejudicar o processo de cicatrização de feridas através da inibição do recrutamento e migração de fibroblastos (NAKAMURA et al., 1995).

Estes mesmos autores estudaram essa migração de fibroblastos em pulmão e há uma hipótese de que o fumo do cigarro pode contribuir para o desenvolvimento de enfisema por inibição da proliferação e migração de fibroblastos, inibindo a reparação do tecido pulmonar já comprometido.

Segundo Wong (2004), a fumaça do cigarro sugere um aumento da adesão celular, o que pode resultar em uma diminuição da migração de fibroblastos para o local da ferida. Durante a cicatrização de feridas normais, estas células migram para a área do tecido danificado, produzem citocinas e fatores de crescimento e depósito e remodelação da matriz extracelular.

Portanto, mesmo se os números de fibroblastos são suficientes para a reparação, eles são incapazes de migrar e podem permanecer concentrados na borda da ferida onde vão depositar o excesso de matriz extracelular, conduzindo a uma cicatrização anormal.

Nesta investigação, o número de fibroblastos nos 3 grupos não indicou diferença estatística significativa $(p=0,29)$, mostrando que apesar do número de fibroblastos suficientes nos 3 grupos, pode não ter havido migração para área da lesão, prejudicando assim a formação do colágeno no grupo 1 e em menores proporções nos grupos 2 e 3 onde a formação do colágeno apresenta-se mais organizada.

O cigarro, como já visto por vários autores, causa um grande impacto em todas as fases da cicatrização e na região da lesão.

Os efeitos tóxicos do cigarro devem-se a redução temporária da perfusão tecidual e oxigenação, ao comprometimento das funções das células inflamatórias e bactericidas, a atenuação reparativa das funções celulares, incluindo a síntese e deposição de colágeno, a atenuação da inflamação e proliferação é responsável pela maior incidência de complicações na cicatrização em fumantes (SORENSEN, 2012).

De acordo com Sorensen (2012), a cessação do tabagismo reverte alguns dos muitos mecanismos relacionados com a cicatrização, mas não todos, porque muitos dos processos patológicos induzidos pelo fumo parecem ser prolongados ou mesmo irreversíveis, apesar de abstinência ao fumar.

A melhoria dos mecanismos da resposta celular inflamatória e bactericida explica a redução de complicações infecciosas de cura após a cessação do tabagismo, em nossos achados encontrou-se infecção no grupo 3 provavelmente pelo maior período de experimentação.

A nicotina parece ter um efeito prejudicial na inflamação e na estimulação da proliferação em modelos de feridas.

Apesar de se conhecer clinicamente a maioria dos efeitos adversos do fumo na cicatrização de feridas, muitos deles não são totalmente comprovados, ou são apenas demonstrados em modelos animais; apesar disso, deve-se evitar o uso da nicotina no pré e pós-operatório para se evitar as complicações que podem surgir de uma cicatrização mais lenta.

\section{CONCLUSÃO}

Os resultados de nosso modelo experimental demonstram que a nicotina administrada na dose de $2 \mathrm{mg} / \mathrm{kg}$ de massa corporal causou no grupo 1, que recebeu nicotina sem interrupções inclusive depois da 
cirurgia, uma menor quantidade de tecido de granulação e o colágeno apresentou-se desorganizado e escasso.

Os resultados do grupo 1 foram comparados com os grupos $2 \mathrm{e} 3$ que interromperam o uso da nicotina antes da cirurgia por uma e duas semanas, respectivamente.

Pode-se concluir que mesmo sabendo que alguns efeitos da nicotina têm caráter irreversível, a interrupção por uma ou duas semanas pode ser benéfica para uma cicatrização sem complicações.

\section{REFERÊNCIAS}

CAMPOS, A. C. 1.; ALVES, M. R.; IOSHII, S. O.; MORAES-JUNIOR, H.; SAKAMOTO, D.; GORTZ, 1. W. Influência da nicotina na proliferação de miofibroblastos e de vasos sanguíneos no tecido cicatricial da parede abdominal de ratos lactentes: estudo imunoistoquímico. ABCD, Arq. Bras. Cir. Dig. v. 23, n. 4, São Paulo, out./dez. 2010. Disponivel em: <http://www.scielo.br/scielo.php?script=sci_arttext\&pid = S010267202010000400003\&1$\mathrm{ng}=\mathrm{pt \& nrm}=\mathrm{iso}>$. Acesso em: 15 fev. 2013.

FANG, Y.; SVOBODA, K. K. H. Nicotine inhibits myofibroblast differentiation in human gingival fibroblasts. J Cell Biochem., v. 95, n. 6, p. 1108-1119, 15, 2005.

GIL, A. C. Como elaborar projetos de pesquisa. 4. ed. São Paulo: Atlas, 2006. p. 47-49.

GUIMARÃES, M. V. T. N.; MOREIRA, G. H. G.; ROCHA, L. P. et al. Ação Da L-Arginina Na Evolução De Retalhos Cutâneos De Ratos Sob Exposição à Nicotina. Rio de Janeiro: Rev. Col. Bras. Cir., 2013. Disponível em: < http://www. scielo.br/scielo.php?script $=$ sci_arttext\&lng $=$ pt\&n$\mathrm{rm}=$ iso\&tlng $=$ pt\&pid $=$ S0100-69912013000100009> . Acesso em: 10 jun. 2013.

KERRIGAN, C. L. Skin flap failure: pathophysiology. Plastic and Reconstructive Surgery, Baltimore, v. 72, p. 766-77, 1983.

LEAL, R. P.; CAMMAROTA, C. M.; SABALCHEIRO, J.; MARQUES, M. M.; MOREIRA, M. Efeitos da Pentoxifilina e o Cloridrato de Buflomedil em Retalhos Randomizados em Ratos sob Influência da Nicotina. Rev. Soc. Bras. Cir. Plást., São Paulo, v. 19, n. 13, p. 31-42, set./dez. 2004. Disponível em: < http://www.rbcp.org.br/imageBank/PDF/19-03-02-pt.pdf> . Acesso em: 04 maio 2013.
MARTIN, P. WoundHealing: aiming for perfect skin regeneration. Science, v. 276, p. 78-80, 1997.

MEDEIROS, A. C.; RAMOS, A. N. O.; DANTAS, A. M.; AZEVEDO, R. C. F.; ARAÚJO, F. L. F. B. Tratamento tópico de queimaduras do dorso de ratos com ácido hialurônico. Acta Cir. Bras, São Paulo, v.14, n.4, dez. 1999. Disponível em: $\quad<$ http://www.scielo.br/scielo.php?script $=$ sci_arttext\&pi

$\mathrm{d}=$ S0102-86501999000400010\&lng $=$ en\&nrm $=$ iso\&tl$\mathrm{ng}=\mathrm{pt}>$. Acesso em: 13 ago. 2013.

MENESES, R. R. et al. Influência da longevidade da solução de Verhoeff na intensidade/especificidade das fibras elásticas, em material biológico de origem suína. Investigação: Revista Técnica de Anatomia Patológica, v. 15, n. 14, p. 10-14, 2011.

MOSELY, L. H.; FINSETH, F. Cigarette smoking: impairment of digital blood flow and wound healing in the hand.The Hand, v. 9, n. 2, p. 97-101, 1977.

NAKAMURA, Y. et al. Cigarette smoke inhibits lung fibroblast proliferation and chemotaxis. Am J RespirCritCareMed., v. 151, p. 1497-503,1995.

PLANETA, C. S.; CRUZ, F. C. Bases neurofisiológicas da dependência do tabaco. Rev. psiquiatr.clín., São Paulo, v. 32, n. 5, set./out. 2005. Disponível em: $<$ http://www.scielo.br/scielo.php?script $=$ sci_arttex$\mathrm{t} \&$ pid $=$ S0101-60832005000500002\&lng $=$ pt\&nrm $=\mathrm{i}-$ so >. Acesso em: 15 fev. 2013.

SANTOS, M. N. F. et al. Avaliação do uso do extrato bruto de Jatropha gossypiifolia L. na cicatrização de feridas cutânea em ratos. Acta Cir. Bras., v. 21, suppl 3, 2006.

SCHENFELDER, G. et al. Avaliação da exposição e interrupção da nicotina em tempos diferentes na evolução de retalho cutâneo ao acaso de dorso de ratos por meio de fluxometria a laser e de picrosirius. Rev. Bras. Cir. Plast., v. 23, n. 4, p. 322-7, 2008.

SILVA, D. T. Uso do ipê-roxo (Tabebuia avellanedae) na cicatrização de feridas cutâneas em ratos. 2006. 97f. Dissertação (Mestrado em Ciência Animal nos Trópicos, na área de Saúde Animal) - Universidade Federal da Bahia, Salvador, 2006. 
SILVA, S. R.; CASTRO, R. C. Fundamento de dermatologia. Rio de Janeiro: Atheneu, 2012. Cap. 1, p.1.

SIMÕES, M. L. P.; TETILLA, M. R.; SIMÕES, R. B.; MARTIN, M. M.; REPKA, J. C. D.; ZANATO, D. A influência da nicotina na densidade de colágeno em cicatrizes cutâneas, em ratos. Rev. Col. Bras. Cir., Rio de Janeiro, v. 36, n. 5. sept./oct. 2009. Disponível em: $<$ http://www.scielo.br/scielo.php?script $=$ sci_arttex$\mathrm{t} \& \mathrm{pid}=$ S0100-69912009000500011\&nrm $=$ iso\&tl$\mathrm{ng}=\mathrm{pt}>$. Acesso em: 14 fev. 2013.

SORENSEN, L. T. Wound healingand infection in surgery: the pathophysiological impactof smoking, smoking cessation, and nicotine replacement therapy a systematic review. Ann Surg., v. 255, n. 6, p. 1069-1079, june, 2012.

SUEHARA, Y. L.; SIMONE, K.; MAIA, M. Avaliação do envelhecimento facial relacionada ao tabagismo. An. Bras. Dermatol., v.81, n.1, 2006. Disponível em: $<$ http://www.scielo.br/scielo.php?script $=$ sci_arttex$\mathrm{t} \& \mathrm{pid}=$ S0365-05962006000100004\&lng $=\mathrm{pt} \& \mathrm{nrm}=\mathrm{i}-$ so > . Acesso em: 18 maio 2013.

WONG, L. S.; GREEN, H.M.; FEUGATE, J.E.; YADAY, M.; NOTHNAGEL, E.A.; MARTINS-GREEN, M. Effects of 'second-hand' smoke on structure and function of fibroblasts, cells that are critical for tissue repair and remodeling. BMC CellBiol, v. 5, n. 13, 2004.

ZIA, S.; NDOYE, A.; LEE, T. X.; WEBBER, R. J.; GRANDO, A. S. Receptor-mediated inhibition of keratinocyte migration by nicotine involves modulations of calcium in flux and intracellular concentration. J Pharmacol ExpTher., v. 293, n. 3, p. 973-981, jun. 2000.

Recebido em: 19 de setembro de 2014 Aceito em: 23 de abril de 2015 